\title{
AbcNum Braille: Proposta de um Aplicativo para Auxiliar no Aprendizado do Alfabeto Braille para Pessoas com Baixa Visão
}

\author{
Wermeson R. Aquino, Zildomar C. Félix, Isledna Rodrigues de Almeida, Ítalo \\ Cesar de Souza Belo
}

Unidade Acadêmica de Serra Talhada - Universidade Federal Rural de Pernambuco

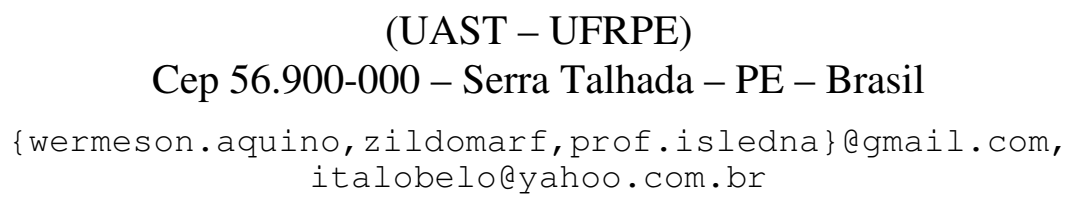

\begin{abstract}
This paper discusses the proposed AbcNum Braille application, which aims to help the Braille alphabet learning for people with low vision through mobile touchscreen devices, so using audible and tactile stimuli promoting the help in learning the vowels, and figures depending on the form of writing and reading universally used as a means of tactile communication Braille system.
\end{abstract}

Resumo. Este trabalho aborda a proposta do aplicativo AbcNum Braille, que tem como objetivo auxiliar na aprendizagem do alfabeto Braille para pessoas com baixa visão por meio de dispositivos móveis touchscreen, utilizando-se de estímulos sonoros e tácteis, promovendo assim um o auxilio no aprendizado das vogais, consoantes e números na forma de escrita e leitura universalmente utilizada como forma de comunicação táctil - O Sistema Braille.

\section{Introdução}

A deficiência visual é um termo que está associado a um estado irreversível de diminuição da capacidade visual de um individuo, ocasionada por fatores congênitos (patogenias) ou ambientais (patologias, lesões, tumores etc) (COSTA, 2004). No Brasil, $18,6 \%$ da população, cerca de 35.791 .488 milhões de pessoas, declararam ter algum tipo de deficiência visual. Destes, 1,6\% dos brasileiros são totalmente cegos e 3,46\% possuem deficiência visual severa (CARTILHA DO CENSO 2010 - PESSOAS COM DEFICIÊNCIA, 2012). Tais deficiências podem ocorrer de duas formas: cegueira ou baixa visão.

As pessoas com cegueira são as que apresentam desde a ausência total de visão até a perda da projeção de luz, o que faz seu processo de aprendizagem ocorrer através dos outros sentidos (tato, olfato, audição e paladar); já àquelas com baixa visão são as que apresentam condições de indicar captação de luz até o grau em que a redução da acuidade visual interfere ou limita seu desempenho. Em ambos os casos, o Sistema Braille pode ser utilizado como principal meio de comunicação escrita (BRASIL, 2006), porém, ele necessita de adaptação para uso com tecnologias móveis de comunicação como smartfones, que apresentam grande adesão mundial, o que pode ser verificado em uma pesquisa feita pelo IDG Global Solutions (IGS) em 16 países, incluindo o Brasil. 
Nessa pesquisa, mais de dois terços dos participantes revelaram que usam um smartphone para fins pessoais, o que indica uma grande demanda por acessibilidade, que no Brasil, conforme a Lei 5.296 de Dezembro de 2004 (BRASIL, 2004), deve ser provida a todos ou ao maior número possível de usuários em situações limitantes.

Perante esse contexto, observa-se que as pessoas com baixa visão enfrentam uma grande barreira na aprendizagem, a limitação visual. Um dos recursos pedagógicos usado na educação para potencializar o ensino é a tecnologia. Pela sua natureza, ela pode aliar tanto o interesse na sua utilização como também a absorção de conteúdo educacional. Diante disso, no presente trabalho se pretende usufruir desse recurso, através de uma aplicação com caráter pedagógico, para auxiliar pessoas com baixa visão no aprendizado do sistema Braille em dispositivos móveis que utilizam a tecnologia touchscreen. O texto está organizado da seguinte forma: A seção 2 apresenta o conceito de baixa visão e o sistema Braille, na seção 3 apresenta-se os trabalhos relacionados, a seção 4 mostra a proposta do AbcNum Braille, e por fim na seção 5 a conclusão.

\section{Baixa Visão e o Sistema Braille}

Também chamada de Ambliopia, Visão Subnormal ou Visão Residual, a baixa visão é uma perda severa da acuidade visual. Geralmente é uma condição na qual a visão de uma pessoa não pode ser totalmente corrigida através de tratamento clínico ou cirúrgico, nem com o uso de óculos convencionais (CARVALHO et at, 1994). Tal situação compromete a funcionalidade, com prejuízo na capacidade de realização de tarefas (BRASIL, 2008). A Organização Mundial de Saúde (OMS) define baixa visão como acuidade visual no melhor olho, com a melhor correção óptica, menor do que 20/60 e maior ou igual a 20/400.

Conceitualmente, só há duas possibilidades de classificação de um deficiente visual, ser cego ou ter visão subnormal. Diante disso, os portadores de baixa visão, mesmo possuindo limitações que não permitem realizar determinadas funções, não podem ser tratados como cegos, uma vez que possuem visão residual que possibilita executar algumas tarefas perfeitamente (ROMAGNOLLI E ROSS, 2008).

\subsection{Sistema Braille}

Essa importante conquista para a educação e integração de DVs na sociedade teve início em 1825, e é utilizada universalmente na leitura e na escrita por pessoas com DVs. Esse sistema de leitura e escrita táctil foi inventado na França por Luis Braille, que era um jovem cego (CERQUEIRA, 2009). Ele foi pensado a partir de seis pontos em relevo, dispostos em forma de matriz $3 \times 2$; essa forma com seis pontos ficou convencionada chamar de "cela Braille". Para uma maior compreensão, os pontos são enumerados na coluna da esquerda, do alto para baixo como 1,2 e 3; já na coluna da direta, do alto para baixo como 4,5 e 6 , conforme pode ser visto na figura 1 .

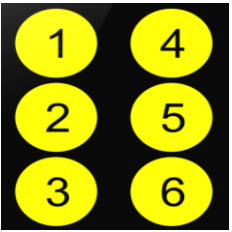

Figura 1. Cela Braille. 
O sistema braille no Brasil está disposto em vinte e seis sinais utilizados para o alfabeto, dez para os sinais de pontuação de uso internacional, correspondendo aos 10 sinais da $1^{\mathrm{a}}$ linha, localizados na parte inferior da cela braille: pontos $2,3,5$ e 6 . Os vinte e seis sinais restantes são destinados às necessidades especiais de cada língua com suas características específicas, por exemplo, a língua portuguesa tem letras acentuadas ${ }^{1}$.

\section{Trabalhos Relacionados}

O Braille Guide (Google Play,2015) é uma aplicação simples para as pessoas que querem aprender braille, o usuário pode escolher entre varias operações, como por exemplo, interagir com a cela braille, ver a lista de caracteres e realizar exercícios de escrita com algumas palavras, além de poder traduzir o alfabeto escrito em caracteres para o braile. Esta aplicação difere do objetivo do trabalho proposto, pois não dispõem de recursos de acessibilidade táctil e o foco não são as pessoas com deficiência visual.

Braille App (Google Play,2014) é uma aplicação gratuita e propicia aos usuários cinco tipos de operações: Transcritor BR, Transcritor PT, Lista de Sinais, Guia de referência e Exercícios. Transcritor BR: transcreve texto em Braille para Português e permite enviar SMS com o texto transcrito por meio de uma célula Braille virtual interativa. Transcritor PT: transcreve textos em Português para Braille. Entretanto é importante destacar que a aplicação Braille App apesar de oferecer diversos serviços, ela não apresenta uma interface de fácil utilização para pessoas com algum tipo de deficiência visual, sendo apenas útil para pessoas que não possuem deficiência visual e que já saibam Braille.

\section{Aplicativo AbcNum Braille}

O AbcNum Braille consistirá em um aplicativo para dispositivos móveis com a tecnologia touchscreen na plataforma Android. O propósito é auxiliar no aprendizado das vogais, consoantes e números representados no sistema Braille, para ajudar pessoas com baixa visão no seu aprendizado. Diante das características de forma de escrita e leitura em Braille, bem como as limitações do público alvo, foi possível enumerar um conjunto de requisitos que o aplicativo terá. Na Tabela 01 são descritos esses requisitos.

Tabela 1. Requisitos principais do AbcNum Braille

\section{Requisitos}

Fornecer feedback sonoro ao usuário (uso de leitor de tela).

Fornecer feedback táctil ao usuário (uso do vibrador do dispositivo).

Permitir que com um simples click possa apenas ouvir e com duplo click acessar funcionalidades.

Permitir que a cela Braille com seis pontos tenha feedbacks diferentes para cada um.

Informar se a sequência digitada na cela Braille é válida.

Usar reforço positive quando houver acerto.

\footnotetext{
${ }^{1}$ SAC (Sociedade de Assistência aos Cegos) http://www.sac.org.br/APR_BR2.htm
} 
Considerando-se os requisitos da tabela 01, o aplicativo AbcNum Braille terá cinco módulos: Vogais, Consoantes, Números, Exercícios e Ajuda. Com essa divisão o usuário poderá se dedicar a aprender somente vogais, consoantes ou números.

Os modulo de vogais, consoantes e números possuem duas etapas, a de apresentação (Figura 2c e Figura 3d), de como são representados esses elementos em Braille, e a de escrita, na qual o usuário se deparará com uma cela Braille e deverá digitar a sequência correspondente ao modulo escolhido. Como exemplo, na Figura 2a vemos a representação da vogal "e", que no alfabeto Braille é formada pelo símbolo 1 e 5. Quando o usuário clicar na bola 1, ele receberá dois feedbacks, um sonoro informando que 1 (um) foi marcado e outro táctil com uma vibração; quando clicar em 5 ouvirá "cinco marcado" e sentirá cinco curtas vibrações. Após isso, o usuário dará um duplo click no botão confirmar, ouvirá a sequência que digitou e o sistema mostrará a vogal na representação do alfabeto brasileiro (Figura $2 b$ ).

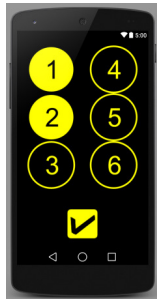

(a)

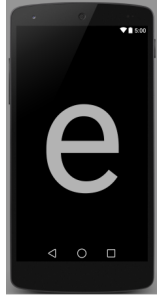

(b)

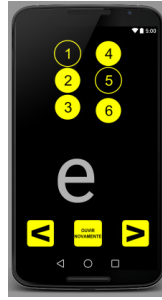

(c)

Figura 2. Interfaces do modulo Vogais do aplicativo AbcNum Braille.

Semelhantemente ao exemplo anterior, vejamos a representação do modulo de números. Os números são representados por duas combinações de celas, a primeira é o "sinal de número", que é formada pela sequência 3, 4, 5 e 6 (essa cela é fixa e precede todos os números); a segunda é formada pela $1^{\text {a }}$ linha Braille, que são as dez letras iniciais do alfabeto (a-j). No exemplo da figura 3, a sequência das celas de sinal de número (Figura 3a) com a consoante "g" (Figura 3b) formará o número 7 (sete) como resultado.

Tendo em vista que quando o usuário seleciona cada ponto da cela, a bola mudará de cor (ficando preta), além disso, receberá o feedback sonoro informando que o ponto " $\mathrm{x}$ " foi marcado, e sentirá " $\mathrm{x}$ " vibrações como feedback táctil, sendo " $\mathrm{x}$ " $\mathrm{o}$ número correspondente a bola selecionada. Quando o usuário digitar a primeira cela (sinal de número - 3,4-5-6) deverá dar um duplo click no botão confirmar e depois repetir o mesmo procedimento para a segunda cela, só que agora com a sequência 1-2-45 , e terá como resposta a interface da figura 3c e um feedback sonoro "Número 7".

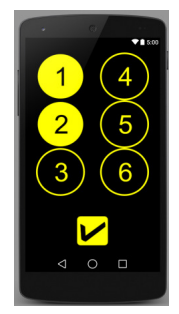

(a)

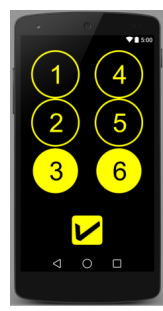

(b)

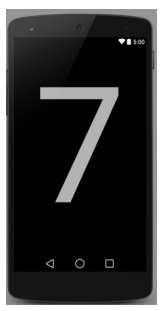

(c)

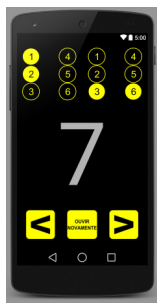

(d)

Figura 3. Interfaces do modulo números do aplicativo AbcNum Braille. 
O AbcNum Braille está em fase de finalização, oferecendo uma gama maior de atividades educacionais, que vai desde o conhecimento do alfabeto e números, até a formulação de escrita de atividades do cotidiano das pessoas. Estas atividades foram desenvolvidas com a ajuda de um professor de Brailler. A aplicação será testada e os resultados serão divulgados em breve.

\section{Conclusão}

Neste trabalho apresenta-se a proposta do aplicativo AbcNum Braille, para auxiliar DV no processo de alfabetização. O software visa permitir que pessoas com baixa visão pratiquem de forma dinâmica e interativa atividades voltadas à alfabetização. A importância do aprendizado do alfabeto Braille para esse público é a conquista de inclusão social, bem como o auxílio no conhecimento de uma forma de leitura e escrita universalmente utilizada. A proposta surge como uma oportunidade para o processo de auxílio no aprendizado de pessoas com visão subnormal, porque congrega em suas funcionalidades diversas características com o retorno táctil e sonoro que poderá auxiliar no processo cognitivo desse perfil de pessoas. A aplicação dispõe de um conceito de interação com recursos tecnológicos que assiste a um publico alvo especifico, os com baixa visão.

\section{Referências}

BRASIL. Decreto 5.296/04, que regulamenta as Leis 10.098/00 e 10.048/00. 2004. Disponível em <http://www.presidencia.gov.br/ccivil_03/_Ato20042006/2004/Decreto/D5296.htm>. Acesso em: 13 jun. 2014.

BRASIL. Ministério da Saúde. Secretaria de Atenção à Saúde. Política Nacional de Saúde da Pessoa Portadora de Deficiência / Ministério da Saúde, Secretaria de Atenção à Saúde - Brasília: Editora do Ministério da Saúde, 2008.

CARTILHA DO CENSO - PESSOAS COM DEFICIÊNCIA, IBGE. Rio de Janeiro: [s.n], 20112.

CARVALHO, K.M.M., GASPARETTO, M.E.R.F., VENTURINI, N.H.B., MELO, H.F.R.. Visão subnormal: orientações ao professor do ensino regular. 2 a ed. Campinas: Editora da UNICAMP; 1994.

CERQUEIRA, J. B.. O legado de Louis Braille. Revista Benjamin Constant, Ed. Especial. Rio de Janeiro: IBCENTRO/MEC, 2009.

COSTA, Luciano Gonsalves. Apropriação tecnológica e ensino: as tecnologias de informação e comunicação e o ensino de física para pessoas com deficiência visual.

GOOGLE PAY. Braille Guide Disponível em < https://play.google.com/store/apps/details?id=com.fiskur.braille\&hl=pt_BR>. Acesso em: 15 de janeiro de 2015

GOOGLE PAY. BrailleApp em <https://play.google.com/store/apps/details?id=com.ailtonluna.brailleappfree\&hl=pt_BR>. Acesso em: 20 de novembro de 2014

ROMAGNOLLI, Glória SE; ROSS, Paulo R. Inclusão de alunos com baixa visão na rede pública de ensino: orientação para professores. Curitiba, 2008. 